\title{
REVIEW ON THE MATERIAL SELECTION FOR THE COMMERCIAL AIR FILTER FOR ATMOSPHERIC AIR
}

\author{
Parikh Naitik Hiteshkumar \\ Department of Mechanical engineering(Thermal) \\ Sal Institute of Technology \& Engineering Research, \\ Opp. Science city, Sola Bhadaj Road, Ahmedabad

\section{Rakesh Prajapati} \\ Department of Mechanical engineering(Thermal) \\ Sal Institute of Technology \& Engineering Research, \\ Opp. Science city, Sola Bhadaj Road, Ahmedabad
}

Abstract - In a modern times development of every sector is very highly made. In urban area are very developing day by day. In every sector the human beings try to make more comfort for themselves. In such a case pollution of air is increase in very high levels. Today, most of city around the world, there is air quality is very poor levels. Today air pollutants as hydrocarbon, soot particles, P.M 2.5 to 10 P.M are main causes of lung dieses. For controlling air pollution many steps are implement by Particular government and also research on them. This studies going to find a more efficient material for Commercial air filter to control a pollutants as hydrocarbon, soot particles, and PM 2.5 tto10PM concentration from Atmospheric air due to developing a material for controlling this particulate and change the material The aim of this research review is To find a more efficient air filter material for commercial dust filter for atmospheric air.

Keywords: Material selection for filter, air filter material, dust filter, filter material

\section{INTRODUCTION}

Urbanization is increase population and then increase in demand for more comfort for their life. From these reasons, the pollution of air is increase day by day. These pollution is very bad impact on human lives and also on earth climate. Due to air pollution earth temperature is highly increase. Source for prevent air pollution are available but there is not much enough. Simple Filteration process diagram shown in fig.1[8]

\section{Saras Patel}

Department of Mechanical engineering(Thermal) Sal Institute of Technology \& Engineering Research, Opp. Science city, Sola Bhadaj Road, Ahmedabad

Harshit Bhavsar

Department of Mechanical engineering(Thermal) Sal Institute of Technology \& Engineering Research, Opp. Science city, Sola Bhadaj Road, Ahmedabad

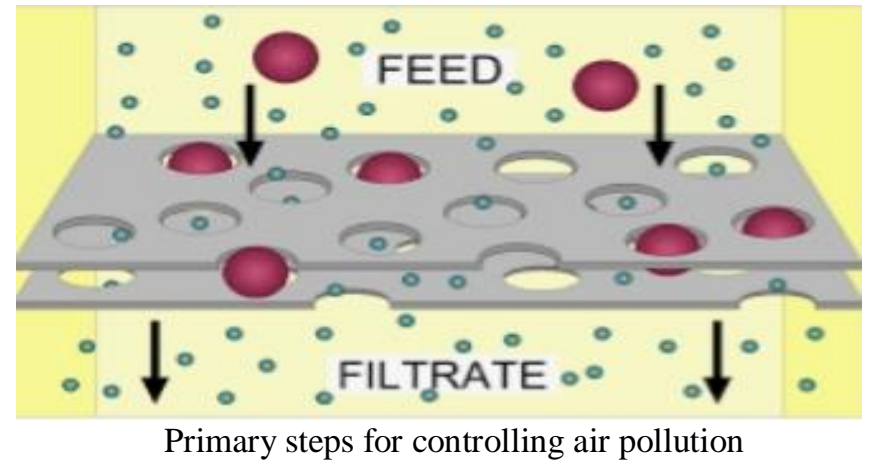

- Need to prevent pollution(dust particles) from construction areas.

- Need to prevent pollution from directly urban area.

- Need to strictly awareness to people for these and also for it's harmful feature.

- Reducing use of fuel like coal, wood in direct environment.

Types of air pollution.

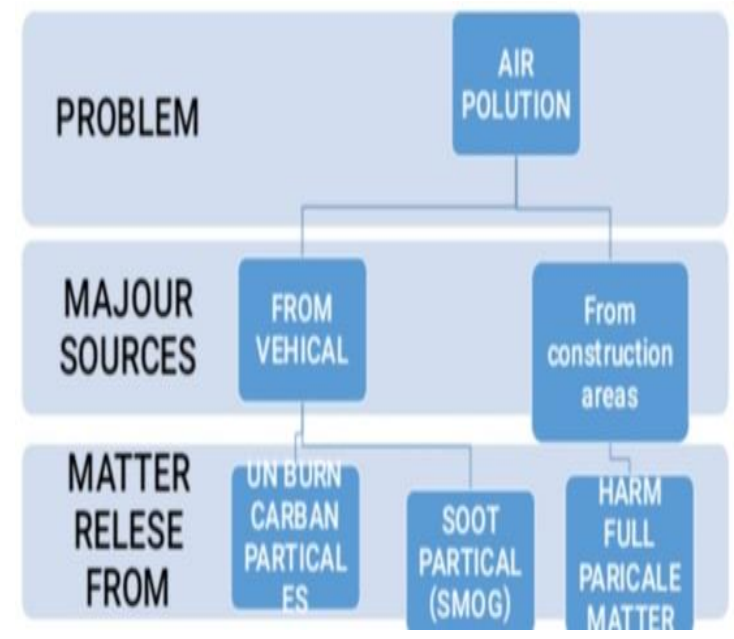


Cyclone saperater :- A cyclone separater remove particulate (soot particles, smog particles \& un burned carbon particles) from air. Fig :-2 [4]

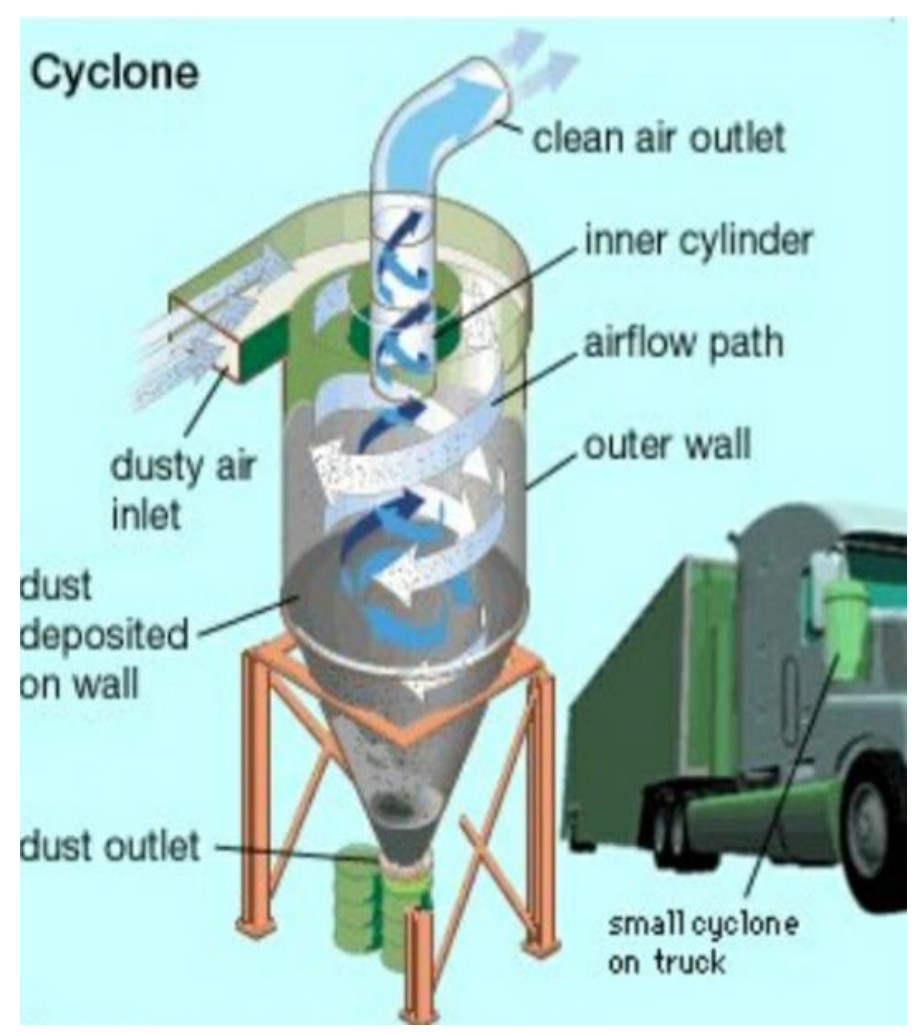

\section{DIFFERENT TYPES OF COMERCIAL AIR POLLUTION CONTROLLING DIVICES}

Air pollution control, the techniques employed to reduces or eliminate the emission into the atmosphere of substances that can harm the environment or human health. To control the air pollution there are some devices. For control particulate:Scrubbers:- Devices called wet scrubbers trap particles by direct contact with a spray of water .

Electrostatic precipitator:- Electrostatic precipitation is commonly used method for removing particulates from air stream, in this particles suspended in air stream are given an electric charge as they enter the unit and are than removed by the influence of an electric field. Fig :3 [4]

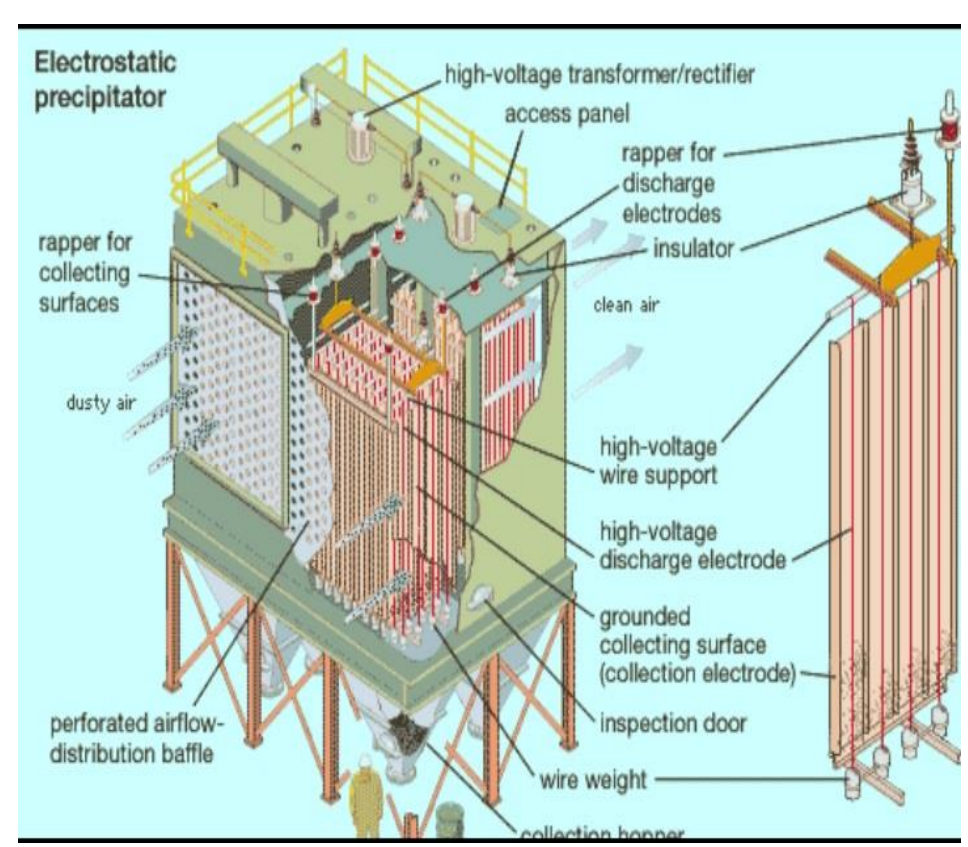

Control of gases:- Gaseous criteria pollutants, as well as volatile organic compounds(VOCs) and other gaseous air toxic, are controlled by three basic methods: absorption, adsorption, and incineration(or combustion).

Absorption :- In the contant of air pollution control, absorption involves the transfer of a gaseous pollutant from the air into a contacting liquid, such as water. Wet scrubbers and packed scrubbers:- it is similar to absorption process.

Flue gas desulfurization :- sulfur dioxide produce in a industries ,power plants by a burning of fossil-fuel which control by absorption process called flue gas desulfurization(FGD). Fig : 5 [4]

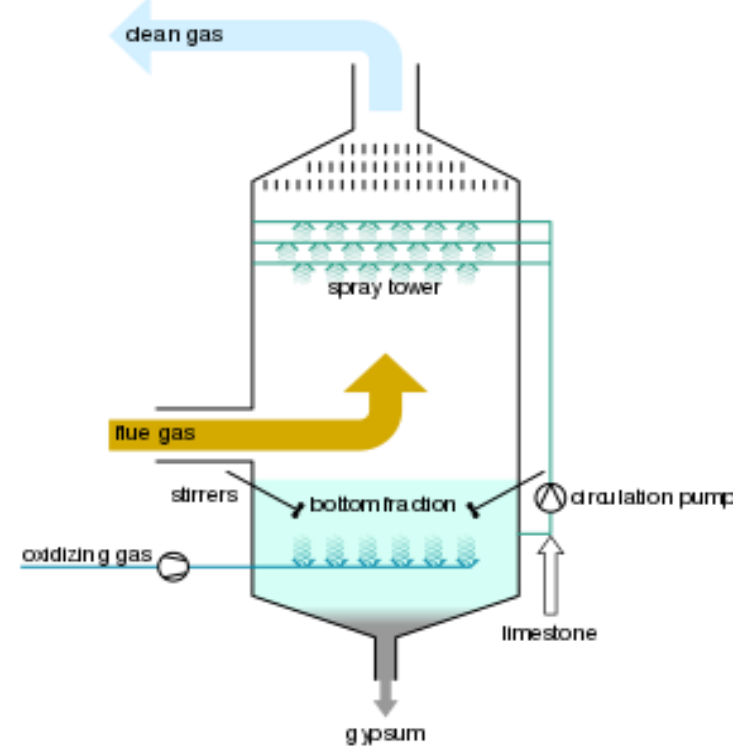


Adsorption:- Adsorption is the process that the particles removed through the collecting on the solid surface. Example is given in fig: 5[8]

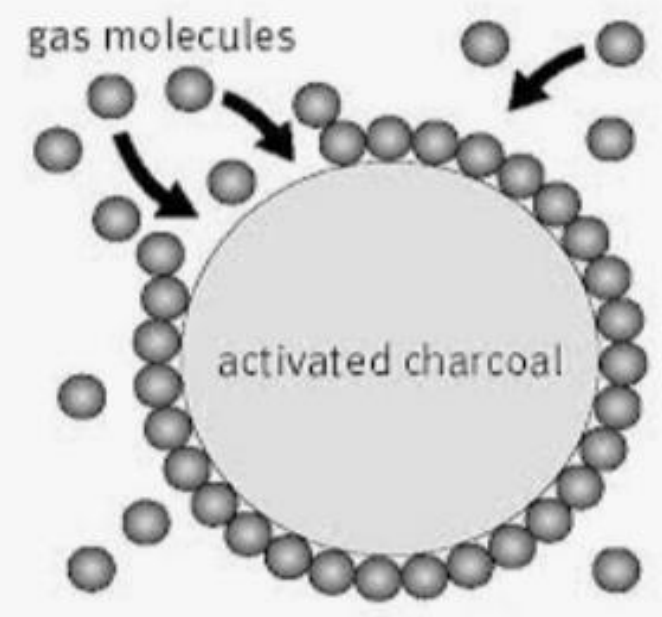

SUMMARY OF DIFFERENT TYPES OF COMERCIAL POLLUTION CONTROL DIVICES

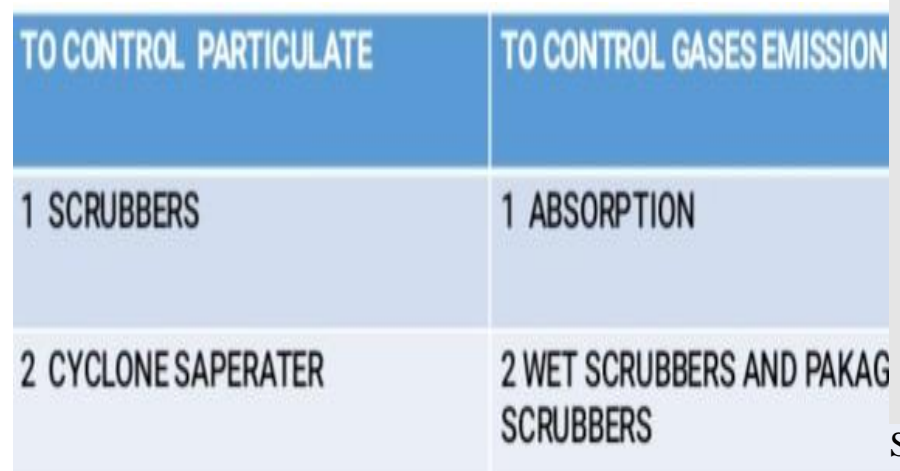

paper is a cheaper than other material. Filter paper in Fig: 6 [11]

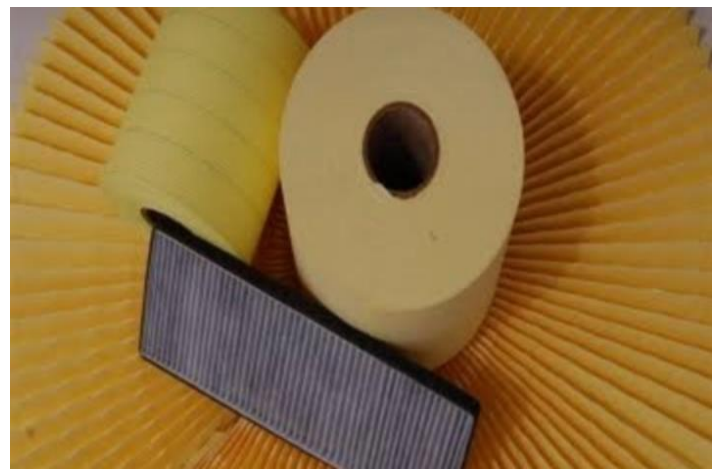

Fiber glass filter for filteration process

- Fiberglass filter material is use for the efficient filteration process for air filter Fiberglass filter are generally pleated type filter is use . It has wide area to filter the air .

Fiber glass filter in Fig : 7 [12]

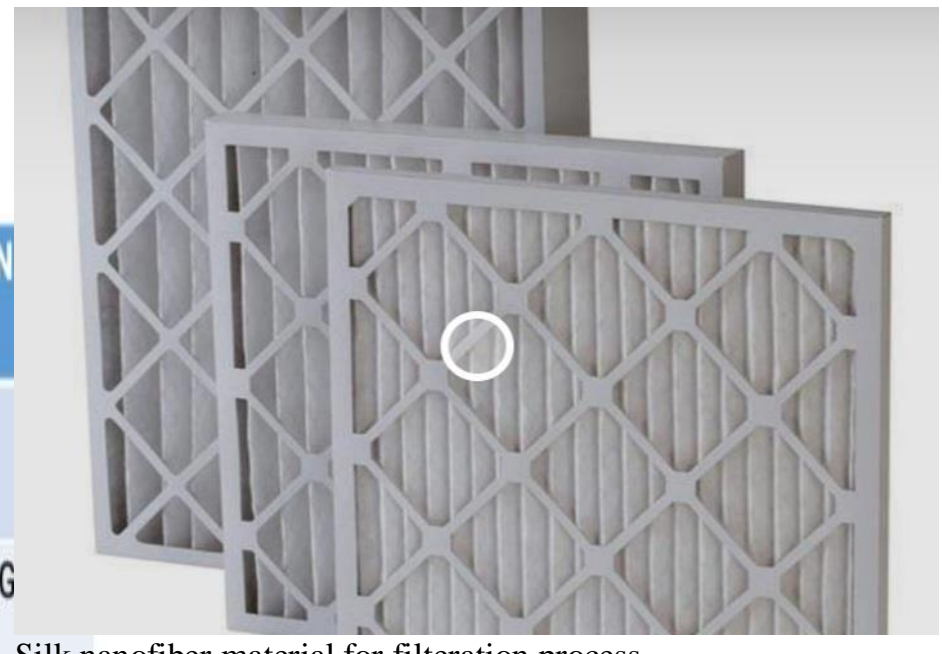

Silk nanofiber material for filteration process.

- Silk is a widely available, edible, biocompatible, and environmentally sustainable natural material.

- silk nanofibers are very effective and good for the filteration process.

- It is light weight and very easily available from the market.

- human-friendly silk nanofiber air filter, which exhibits superior filtration efficiency for both PM2.5 and submicron particles with obviously low pressure drop and low basis weight compared to typical commercial microfiber air filters. Different silk nanofibers shown in fig :8 [7]

\section{MATERIAL SELECTION FOR AIR FILTERATION PROCESS.}

- In the material selection there are a many types of material are use for the air filteration Process.

Filter paper for the filteration process

- It is a common material which is widely use for the air filteration process. Comparatively others materials the filter 

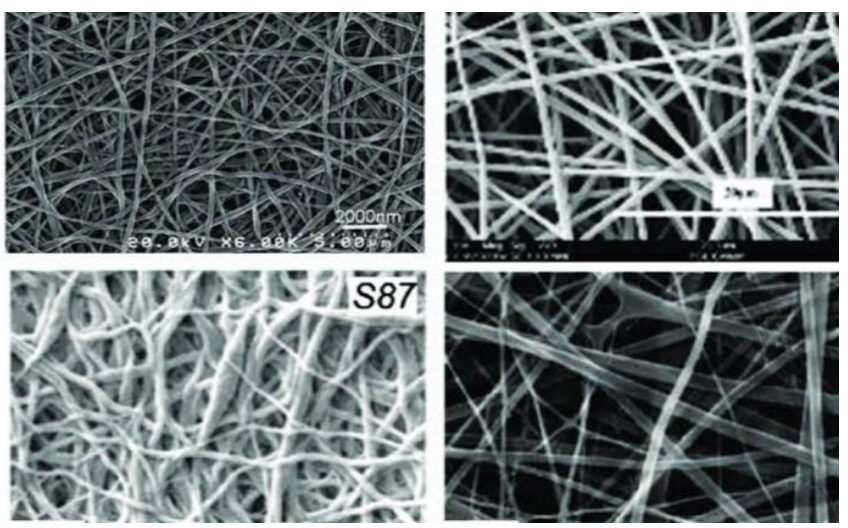

Transparent air filter material

- This material is a transparent material. The material has a highest efficiency to filteration for air compared to pouros material filteration capacity. Transparent filter material shown in fig : 9 [10]
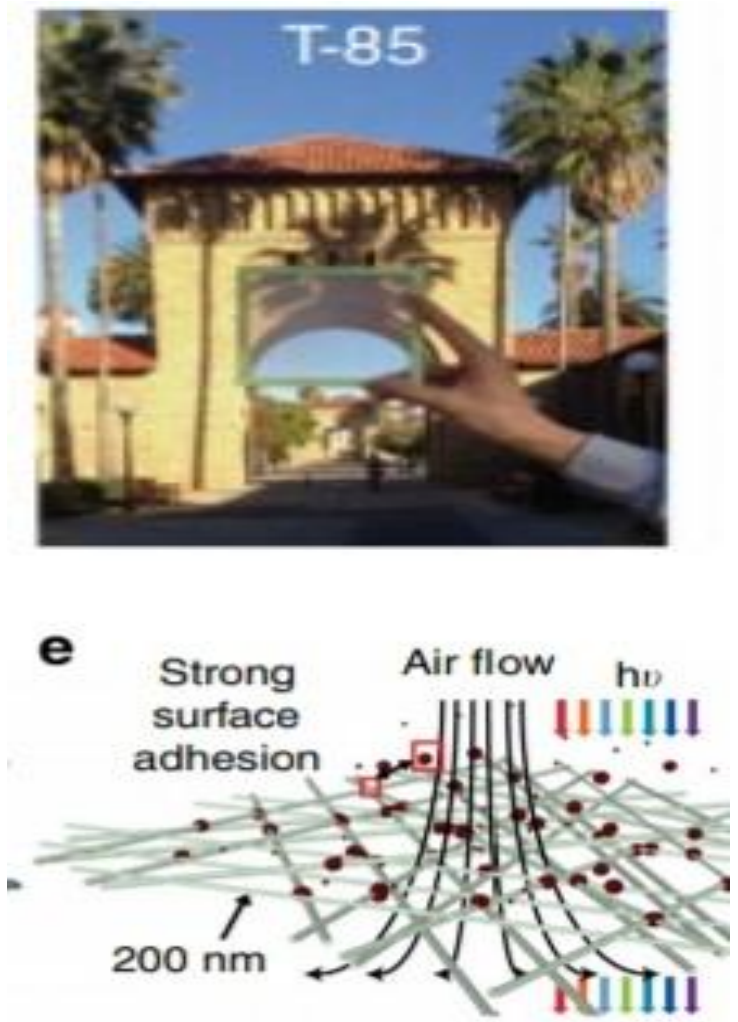

Transparent air filter

Charcoal air filter material

- This material is use for the controlling dust particles and smog particles from the atmosphere. This material are easily available and very cheap compared to other material . In this material while it is in use, a duration of some time period it is required maintenance ( cleaning and washing). After maintenance this is use for the air filteration process. Charcoal air filter material shown in fig: $10,[11]$

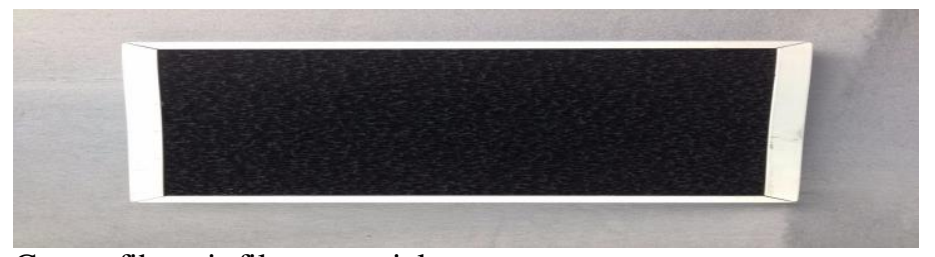

Cotton fiber air filter material

- This filter material is widely used for the air filteration process as well as water filteration process. This material is very easily available. Cotton fiber filter is washable so the usage of this filter material is long time period. This material is generally used for controlling dust particles from atmospheric air. Cotton fiber air filter material shown in fig:11.[11]

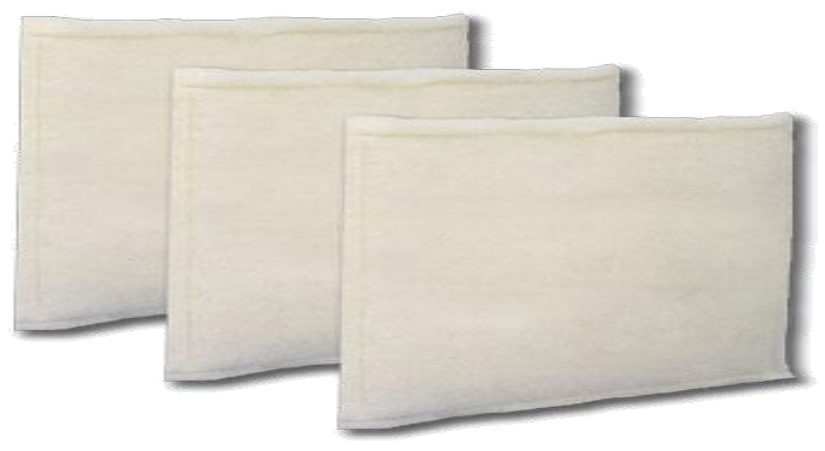

III. LITERATURE REVIEW

PAPER NO :-1

TITLE:- National air quality index.

AUTHOR: - Published by pollution control board of India PUBLISHED YEAR:- 2014

OUTCOMES:- it is a decision making for controlling pollution in cities. concept of an air quality index (AQI) that transforms Weight The values of individual air pollution related parameters (e.g. $\mathrm{SO} 2, \mathrm{CO}$, visibility, etc.) into a single number or set of numbers is widely used for airs quality communication and decision making in many country.

\section{PAPER NO :- 2}

TITLE:- A review of air filteration technologies for sustainable and healthy building ventilation.

AUTHOR:- Guoliang liu , Manxuan Xiao, Xingxing Zhang, Csilla gal, Xiangejie chen,LiuLiu,Songpan, Jinshun wu , Liewellyn Tang, Derek clements-croome

PUBLISHED YEAR:- 2017 PUBLISHED JOURNAL :Elsevier ( university of reading)

OUTCOMES :- This is the study about Sustainable and healthy indoor environments have received much attention 


\section{International Journal of Engineering Applied Sciences and Technology, 2021 \\ Vol. 5, Issue 11, ISSN No. 2455-2143, Pages 138-144 \\ Published Online March 2021 in IJEAST (http://www.ijeast.com)}

over the year. Studies, aiming to reduce or remove possible sources of indoor air contaminants from consumer goods and building products, have effectively halted the deterioration of indoor air quality.

\section{PAPER NO :- 3}

TITLE:- Equipments used for environment air pollution control

AUTHOR :- M. K. KaushiK, Chirag kakkar.

PUBLISHED YEAR:- 2007

PUBLISHED JOURNAL :- Research gate OUTCOMES :-

This paper conclude with the statement that the various equipments that can control air pollution from various industries must be used in order to maintain the ecological balance of our environment .

\section{PAPER NO :- 4}

TITLE:- Enhancing indoor air quality - the air filter advantage.

AUTHOR :- Vannan Kandi Vijayan, Haralappa Paramesh, Sundeep Santosh Salvi, Alpa anil Kumar Dalal

PUBLISHED YEAR:- 2016

PUBLISHED JOURNAL :- Lung india publication.

OUTCOMES :- This paper conclude Studies appear to suggest, that reduction in particulate matter and allergens results in reducing symptoms and in certain cases, preventing disease progression across all age groups, including the elderly and children. The evidence is apparent, in chronic respiratory diseases, such as asthma and in cardiovascular health.

\section{PAPER NO :- 5}

TITLE:- Design and fabrication of solar powered air purifier. AUTHOR :- Manjeet Kumar, Satinder Jeet Singh, Prabhat Kumar Shukla, Raj Varun Singha,Manash Dey, Ashutosh Singh

PUBLISHED YEAR:- 2018

PUBLISHED JOURNAL :- International research journal of engineering and technology.

OUTCOMES :-This paper include solar powered air purifier .It reduces particulate level to satisfactory position where a person does not need to worry about pollution related problems . A pure and clean air is right of a human being and all other living creatures on this earth and this project is a small effort from our side to give the all their right. Also in future, modifications can be made to improve working efficiency without effecting setup.

PAPER NO :- 6

TITLE:- Transparent air filter for high efficiency capture AUTHOR :- Chong liu ,Po chun Hsu, Hyun -wook lee, meng ye, Guangyuan zheng, Nian liu Weiyang Li \& Yi Cui .

PUBLISHED YEAR:- 2015

PUBLISHED JOURNAL :- Nature communication OUTCOMES :- Controlling air pollution by the smog particles with the transparent filter. In this paper the filter process is more effective than regularly filter process.

PAPER NO :- 7

TITLE:- Silk nanofibers as high efficient and lightweight air filter.

AUTHOR :-Chunya Wang1, Shuyi Wu2, Muqiang Jian1, Jiarong Xie3, Luping Xu2, Xudong Yang2,3, Quanshui Zheng2, and Yingying Zhang1

PUBLISHED YEAR :- 2016

PUBLISHED JOURNAL:- Tsinghua University Press and Springer-Verlag Berlin Heidelberg 2016

OUTCOMES :- In summary, demonstrated that a lightweight SF nanofiber membrane could be utilized as an air filter with excellent filtration performance for both PM2.5and submicron particles. Free-standing SF nanofiber membranes showed filtration efficiency of $98.8 \%$ for PM2.5 and $96.2 \%$ for 300$\mathrm{nm}$ particles with a lower pressure drop than commercial microfiber membranes with comparable filtration efficiency. The basis weight of a SF nanofiber membrane is only 3.4 $\mathrm{g} / \mathrm{m} 2,1 / 60$ th of a typical commercial respirator with similar filtration

efficiency.

\section{PAPER NO :- 8}

TITLE :- Design and Fabrication of Economical Air Filter

AUTHOR :- Dr. B. Vijaya Kumar1, M. Naveen2, P. Kalyan2, P. Bhavana2, K. Nikhil2

PUBLISHED YEAR :- 2019

PUBLISHED JOURNAL :- International Journal of Trend in Scientific Research and Development (IJTSRD)

OUTCOMES :- The Project Designed and analyzed and satisfies all the necessary conditions for an efficient, economical air filter. The different layers of filters used are just simple and easily available materials (filtrates). The four layer filtration makes us more possible for an effective filtration process. The filtrates cotton, gauge cloth, absorbent cloth and filter cloth are arranged according to the porosity and thus different sized particles set filtered at different positions or segments of filtrates. This form draws air into the filter and filtration takes place. The analysis of the designed filter is also done and an appreciable results are its outcome. Thus this project fetched one of the most simplest and economical air filter.

\section{PAPER NO :- 9}

TITLE : - Removal of VOCs and Improvement of Indoor Air Quality Using Activated Carbon Air Filter.

AUTHOR :- Sujon Mondale, Purna saha.

PUBLISHED YEAR :- 2019

PUBLISHED JOURNAL :- Research gate

OUTCOMES :- Different Techniques of Activated Carbon Based Air Filters have been discussed in this study. Adsorption and commercially available filters using activated carbon are efficient methods of air purification. Based on the 


\section{International Journal of Engineering Applied Sciences and Technology, 2021 \\ Vol. 5, Issue 11, ISSN No. 2455-2143, Pages 138-144 \\ Published Online March 2021 in IJEAST (http://www.ijeast.com)}

study following observations can be made- 1. Bamboo Based Activated Carbons Have Highest Adsorption Efficiency. 2. Activated Carbon Fibers Have Better Effective Surface Area Than Other Materials.

\section{III (A)Observations}

Reviewing the different types of material and their ability for the filteration process for air that, different types of material are use for the different purposes for controlling air pollutants. Every material has a efficient working capacity. Fiber glass filter are very use for the air filteration process for controlling the Vocs. Fiberglass filter is a pouros type material which generally passes to a small particle from its and larger particles are kept on its surface. Filter paper material are also use for the controlling air pollutants like a $\mathrm{HC}$ and dust particles. Filter paper are the generally available in multiple combinations of filter paper arranged in pleated type design. Silk nanofiber material are also used for the filteration process but they are costly compared to other materials. Advantages of silk nanofiber material is that, it has very light weight material. Transparent material for filter has a very high quality efficiency for the filteration process for air. This material has a good filteration capability compared to other pouros type filter material. Charcoal air filter material is very efficient to control the dust particles, smog particles and VoCs. This filter material are washable and also use for a long time period. Cotton air filter material are use for the controlling the dust particles. The cotton filter are easily available and very cheap compared to other. The cotton air filter are washable so, that use of cotton filter are long time period.

\section{III (B)DISCUSSION}

Discussing the different air filters material, that are some advantages of this material which are use for the air filteration process on above observation the Transparent air filter material are high efficient compared to other types of air filter material. Also the tranceparent material is use for the long time period.

\section{CONCLUSION}

Regarding above study about different types of material for air filteration process, the outcome of study is that, the transparent filter material has a good and efficient capability for air filteration process because it performance to removing the Pm2.5 is $98.69 \%$. And also the cotton fiber (pleated type filter) are also good for the air filteration process.

\section{REFERENCE}

[1].Pollution control Board india.,Air Quality Index http://www.indiaenvironmentportal.org.in/files/file/Air\%20Qu ality\%20Index.pdf

[2].Vannan Kandi Vijayan, Haralappa Paramesh, Sundeep Santosh Salvi, Alpa anil Kumar Dalal.(2016) Enhancing indoor air quality -The air filter advantage http://www.lungindia.com on Wednesday, September 28, 2016, IP: 109.88.219.124]

[3]. M. K. KaushiK, Chirag kakkar.,Equipments used for Environment And Pollution control.(2007).See discussions, stats, and author profiles for this publication at: https://www.researchgate.net/publication/305755229 [4]. Liu, G., Xiao, M., Zhang, X., Gal, C., Chen, X., Liu, L., Pan, S.,Wu, J., Tang, L. and Clements Croome,D.A review of air filtration technologies for sustainable and healthy building ventilation (2017). Sustainable Cities and Society, 32. pp. 375396.ISSN https://doi.org/10.1016/j.scs.2017.04.011Available 22106707doi: http://centaur.reading.ac.uk/71549/

[5].Manjeet Kumar, Satinder Jeet Singh, Prabhat Kumar Shukla, Raj Varun Singha,Manash Dey, Ashutosh Singh.,(2018).,Design and Fabrication of Solar Powered Air Purifier . International Research Journal of Engineering and Technology (IRJET) www.irjet.net e-ISSN: 2395-0056 p-ISSN: 2395-0072

[6].Jerry A. NathansonAir pollution control Article written by : content on http://www. britannica.com > air pollution control.

[7].Chunya Wang1, Shuyi Wu2, Muqiang Jian1, Jiarong Xie3Luping Xu2Xudong Yang2,3, Quanshui Zheng2 , and Yingying Zhang.,(2016).Silk nanofibers as high efficient and lightweight air filter.

www.theNanoResearch.com/www.Springer.com/journal/1227 4

[8]. By Anne Marie Helmenstine, Ph.D. January 29, 2020 tration Definition and Processes (Chemistry)filtration: What It Is and How It's Done . https://www.thoughtco.com/filtrationdefinition adsorbpositionprocess 4144961\#text=Filtration\%20is\%20a\%20process \%20usedfilter $\% 20$ is $\% 20$ called\%20the\%20filtrate.

[9]. Dr. B. Vijaya Kumar1, M. Naveen2, P. Kalyan2, P. Bhavana2, K. Nikhil2.,(Mar-Apr 2019),,Design and Fabrication of Economical Air Filter. International Journal of Trend in Scientific Research and Development (IJTSRD) Volume: 3 | Issue: 3 | Available Online: www.ijtsrd.com eISSN: $2456-6470$

[10] Chong liu ,Po chun Hsu, Hyun -wook lee , meng ye, Guangyuan zheng , Nian liu Weiyang Li \& Yi Cui.,(2015).Transparent air filter for high-efficiency PM2.5 capture . .NATURE COMMUNICATIONS | 6:6205 | DOI: 10.1038/ncomms7205

www.nature.com/naturecommunications

[11] Brook, R. D. et al. (2010).,Particulate matter air pollution and cardiovascular disease an update to the scientific 
statement from the american heart association.

Circulation 121, 2331-2378.

[12] Nel, A.(2005).,Air pollution-related illness: Effects of particles. Science , 308, 804-806.

[13] Wang, C.-S.; Otani, Y.(2013).Removal of nanoparticles from gas streams by fibrous filters: A review. Ind. Eng. Chem. Res. , 52, 5-17.

[14] Wang, C. Y.; Li, P.; Zong, Y. C.; Zhang, Y. Y.; Li, S. Q.; Wei, F. (2014).,A high efficiency particulate air filter based on agglomerated carbon nanotube fluidized bed. Carbon , 79, 424-431.

[15] World Health Organisation.[Last accessed on 2015 Aug 20]Ambient (outdoor) Air Quality and Health, Fact Sheet No. 313. Available from: http://www.who.int/mediacentre/factsheets/fs313/en/. 